\title{
Somatic pharmacogenomics of gastrointestinal stromal tumor
}

\author{
Gloria Ravegnini, Patrizia Hrelia\#, Sabrina Angelini" \\ Department of Pharmacy and Biotechnology, University of Bologna, Bologna 40126, Italy. \\ \#These authors equally contributed to this work.
}

Correspondence to: Prof. Sabrina Angelini, Department of Pharmacy and Biotechnology, University of Bologna, Bologna 40126, Italy. E-mail: s.angelini@unibo.it

\begin{abstract}
How to cite this article: Ravegnini G, Hrelia P, Angelini S. Somatic pharmacogenomics of gastrointestinal stromal tumor. Cancer Drug Resist2019;2:107-15. http://dx.doi.org/10.20517/cdr.2019.02
\end{abstract}

Received: 7 Dec 2018 First Decision: 21 Dec 2018 Revised: 24 Jan 2019 Accepted: 11 Feb 2019 Published: 19 Mar 2019

Science Editor: Enrico Mini Copy Editor: Cai-Hong Wang Production Editor: Huan-Liang Wu

\begin{abstract}
Gastrointestinal stromal tumors (GISTs) are rare entities, which, however, represent the most common mesenchymal tumor of the gastrointestinal tract. The discovery of gain of function mutations on KIT and PDGFRA receptor genes led to a deep revolution in the knowledge of this tumor. This paved the way to the introduction of imatinib and other tyrosinekinase inhibitors (TKIs), which terrifically revolutionized the prognosis of GIST patients. Currently, it is well established that tumor mutational status is the main player in clinical outcome; however, with the research advances, it has been slowly understood that GIST landscape is more complex than expected and the TKIs available are not effective for all the GIST subtypes. For this reason, in the era of tailored/personalized medicine, each GIST patient should be considered individually and genetic consult should be the first step to take in consideration in the therapeutic decision making process.
\end{abstract}

Keywords: Gastrointestinal stromal tumor, imatinib, pharmacogenomics, pharmacogenetics, tyrosine-kinase inhibitors

\section{INTRODUCTION}

Gastrointestinal stromal tumors (GISTs) are rare entities, which, however, represent the most common mesenchymal tumor of the gastrointestinal system ${ }^{[1,2]}$. Before the groundbreaking identification of activating mutations in the KIT tyrosine kinase receptor $(T K R)$ gene in $1998^{[3]}$, GISTs were considered as a devastating disease due to scarce response to chemotherapy and radiotherapy. Luckily, the discovery of gain-of-function mutations on KIT and PDGFRA receptor genes led to a deep revolution in the knowledge of this tumor and

cC (i) (c) The Author(s) 2019. Open Access This article is licensed under a Creative Commons Attribution 4.0 International License (https://creativecommons.org/licenses/by/4.0/), which permits unrestricted use, sharing, adaptation, distribution and reproduction in any medium or format, for any purpose, even commercially, as long as you give appropriate credit to the original author(s) and the source, provide a link to the Creative Commons license, and indicate if changes were made. 
from a poor characterized entity, GIST became a paradigm of target therapy. Indeed, at the beginning of 2000, the FDA approved the tyrosine kinase inhibitor (TKI), imatinib, for the management of metastatic and inoperable GISTs. Imatinib - the magic bullet, originally developed for chronic myeloid leukemia - is the first example of molecular-targeted drug with a known mechanism of efficacy; it represents the worldwide paradigm of targeted therapy specifically tuned $v s$. specific molecules - peculiar of the cancer cells ${ }^{[4]}$.

\section{GIST}

After the identification of driver genetic events in 1998 and until a few years ago, GISTs were classically dichotomized in KIT/PDGFRA mutant (about 85\%-90\%), or KIT/PDGFRA wild-type (WT) GISTs or, often called, WT GISTs. WT GIST are a small group harboring a plethora of alterations on different genes, including succinate dehydrogenase $(S D H), N F 1, B R A F, K R A S^{[5,6]}$. However, with the fast advances in sequencing technologies, different studies have showed novel genetic mutations in the WT GISTs subgroup. It became clear that GISTs are a heterogeneous family of tumors, fragmented in different subtypes with specific and peculiar features ${ }^{[7,8]}$, which influence prognosis as well as clinical outcome. In 2014, a report from NIH suggested to classify GISTs in SDH competent, with characteristics in common with the classic KIT/PDGFRA mutant GISTs, and SDH-deficient ${ }^{[9]}$.

\section{SDH competent GISTs}

\section{KIT/PDGFRA mutation}

As previously mentioned, the majority of GISTs harbor a mutation in KIT or PDGFRA genes. Specifically, approximately $80 \%$ of GISTs carry pathogenic activating mutations on KIT, whereas 5\%-10\% harbor PDGFRA mutations ${ }^{[10,11]}$. These mutually exclusive mutations are gain of function mutations, leading to a constitutively and ligand independent activation. This means that the receptors promote the activation of downstream pathways involved in many key biological processes of carcinogenesis, including RAS/RAF/MEK and PI3K/ AKT/mTOR, and MAPK cascades ${ }^{[12,13]}$. Genetic alterations in KIT or PDGFRA genes - that can be simple aminoacid substitutions, in frame deletions or insertions - involve two main regions of the receptors, the regulatory domains and the enzymatic domains. Considering KIT receptor, the vast part of mutations $(\sim 65 \%)$ involve the exon 11 , followed by $10 \%$ of cases who present a mutation on exon 9 . In rare cases ( $2 \%)$, primary KIT mutations can also hit exon 13 and exon 17. With regard to PDGFRA, the most common mutation ( $5 \%)$ affects the exon 18 at codon 842 , and promotes a substitution of an aspartic acid (D) with a valine $(\mathrm{V})(\mathrm{D} 842 \mathrm{~V})^{[14]}$, while mutations on exon 12 and 14 are less frequent ${ }^{[14]}$. The main difference between KIT and PDGFRA mutation is the location within the receptor. Indeed, the majority of KIT mutations in GISTs arise in the juxtamembrane domain (exon 11), but only 10\% of PDGFRA mutations are in this region (exon 12). On the contrary, alterations within the activation loop of KIT (exon 17) are rare events $(<1 \%)$, but are prevailing in PDGFRA-mutant GISTs (exon 18) ${ }^{[15]}$.

\section{BRAF/RAS and NF1 mutant GISTs}

Among the SDH competent GISTs are included BRAF/RAS mutant and NF1 mutant GISTs. GISTs with mutations in BRAF/RAS or NF1 might be referred to as RAS-pathway mutant GISTs. It is estimated that among patients with no mutations on KIT or PDGFRA (KIT/PDGFRA WT), 5\%-13\% may have a genetic alteration on BRAF; in particular, $>90 \%$ of BRAF mutations occur in exon 15 on codon 600 , usually $\mathrm{V} 600 \mathrm{E}^{[16-18]}$. The $\mathrm{V} 600 \mathrm{E}$ mutation promotes a BRAF activity due to creation of a salt bridge with the residue K507. V600E-K507 interaction mimics the conformational changes occurring during dimerization, so that BRAF V600E does not depend on dimerization for increased kinase activity ${ }^{[19]}$. BRAF is an intracellular protein kinase, playing a critical role in the RAS-RAF-MEK-ERK signaling pathway. Mutations on KRAS are events even more rare than BRAF ones; KRAS mutations in GISTs have a low frequency, spanning from $\sim 1 \%$ to $11 \%$ of KIT/PDGFRA WT GIST ${ }^{[16]}$. Besides the mutations on BRAF/RAS, it has been reported that the autosomal-dominant inherited disease, neurofibromatosis Type 1 (NF1), promotes an increased incidence of GIST. In general, about 7\% of cases with NF1 mutations will develop a GIST during their lifetime. This type 
of neurofibromatosis is characterized by genetic alterations on NF1 gene, which had more than 60 exons, and encodes neurofibromin, a tumor suppressor that downregulates the RAS/RAF/MEK/ERK pathway ${ }^{[20]}$.

\section{SDH deficient GISTs}

The SDH deficient GISTs' group includes GIST patients who lost the SDH complex functionality. Indeed, 10\%-15\% of adult GISTs do not harbor genetic alterations on KIT or PDGFRA but present alterations on one of the $S D H$ genes. SDH is a mitochondrial enzyme composed by four different subunits, encoded by four different genes $S D H A, S D H B, S D H C$, and $S D H D^{[8]}$. The SDH loss of expression is often due to germline and/or somatic loss-of-function mutations in any of the SDH subunits. In addition to the canonical DNA mutations, recently, different papers have showed that SDH inactivation may be due to epigenetic mechanisms as hypermethylation of SDHC promoter $^{[21]}$. The SDH-complex is involved in the Krebs cycle and is responsible for the conversion of succinate to fumarate. Consequently, SDH deficiency leads to accumulation of succinate, which in turn promotes HIF1a overexpression and expression of hypoxiaassociated tumorigenic responses and angiogenesis ${ }^{[22]}$. Considering the clinical features, SDH-deficient GISTs show a number of unique characteristics, such as young age at onset, female gender predilection, gastric localization, frequent lymph node metastatic involvement, and an indolent behavior ${ }^{[7,23]}$.

\section{TREATMENT OF GIST}

GIST management for immunohistologically confirmed GISTs plans: (1) surgical resection for resectable GISTs without metastasis, or (2) administration of TKIs for unresectable, metastatic, or recurrent GISTs ${ }^{[24-26]}$. Currently, the only first-line approved treatment for metastatic and inoperable GIST is imatinib. Imatinib, introduced in GIST management at the beginning of 2000, deeply changed the prognosis of these patients, who were considered irresponsive to the majority of available chemotherapic treatments ${ }^{[27]}$. Imatinib is a selective TKI, which targets diverse tyrosine kinase receptors, including ABL, BCR-ABL, KIT, PDGFRA, PDGFRB and CSF1R. The majority of GISTs respond well to the imatinib standard dose of $400 \mathrm{mg} / \mathrm{day}$, but, commonly, after 24-36 months, a large proportion of patients develop secondary mutations and the tumor progresses $^{[28]}$. To face the progressive acquisition of resistance, within the last 20 years, a second and a third line, sunitinib and regorafenib, respectively - have been introduced in GIST management. Sunitinib and regorafenib are TKIs ${ }^{[29,30]}$ with a wider range of kinase inhibition - compared to imatinib, including KIT, PDGFR, VEGFR, FLT3, TIE2, RET, FGFR1, RAF ${ }^{[30,31]}$. However, despite the efficacy of the currently available three-lines of therapy, patients usually progress even under sunitinib and regorafenib; unfortunately, there are no other therapeutic options and rechallenge of imatinib or sunitinib may represent a reasonable option in advanced GIST patients after failure of previous treatments ${ }^{[32]}$. In the last years, the research progress and the advance in deep sequencing techniques promoted the identification of novel potential targets and different trials are ongoing.

\section{KIT/PDGFRA genotype and clinical outcome}

It is well established that tumor genotype play a critical role in GIST clinical outcome. Indeed, among GIST patients treated with TKIs, it has been observed a wide inter-individual variability and mutational analysis appear to be critical to make a clinical decision about adjuvant therapy.

Patients may show a primary resistance to the treatment (i.e., fail to respond within the first 6 months of treatment), or, as often happens in GISTs, stop to respond at some point, after an initial response (secondary or acquired resistance during treatment $)^{[33]}$. It has been reported that about $10 \%-15 \%$ of GISTs treated with imatinib show primary resistance. Specifically, a meta-analysis of four studies involving 215 GIST patients evaluated resistance according to KIT and PDGFRA genetic alteration ${ }^{[34]}$. The authors found that $50 \%$ of PDGFRA-mutant, $\sim 35 \%$ of KIT/PDGFRA wild-type and $\sim 10 \%$ of KIT mutant GISTs were irresponsive to imatini $^{[34]}$. Considering the lack of an oncogenic mutation, it is not surprising the low imatinib response observed in KIT/PDGFRA WT GIST. 
With regard to the other KIT/PDGFRA mutant GISTs, the mechanisms of primary resistance is quite unexpected. However, the most common PDGFRA mutation, $\mathrm{D} 842 \mathrm{~V}$, is considered imatinib resistant; this is due to a conformational change located within the receptor activation loop which makes imatinib unable to bind it $^{[1]]}$.

Given the frequency, KIT mutant GIST patients have been studied more extensively than other subtypes.

Mutations on KIT exon 9, accounting for $\sim 10 \%$ of GIST cases, are frequently characterized by duplications of six nucleotides (nt, encoding Ala-Tyr) at position 502-503, located within the extracellular domain. It is thought that the consequence of this duplication is an alteration in the receptor conformation, which mimics the binding of the physiological ligand, the stem cell factor, thus promoting constitutive activation ${ }^{[8]}$. In vitro studies have proven that mutations on KIT exon 9 reduce the sensitivity to imatinib ${ }^{[35]}$. Furthermore, presence of exon 9 mutations has been reported as the strongest adverse prognostic factor for imatinib response, and increases the relative risk of progression and death by $171 \%$ and $190 \%$ respectively, with respect to KIT exon 11 GISTs $^{[36]}$. Results from different studies have shown that KIT exon 9 GISTs benefit from higher dose of imatinib, with significantly better progression-free survival (PFS) ${ }^{[35,37,38]}$. For this reason, this subset of patients is treated with $800 \mathrm{mg}$ per day of imatinib, (instead of $400 \mathrm{mg}$ ), which is now considered the standard dose for this subgroup. In addition, for metastatic GISTs, it is strongly recommended that the treatment is continued indefinitely, as it has been observed that treatment outage is usually followed by quick tumor progression ${ }^{[24]}$. ESMO-EURACAN Clinical Practice Guidelines for diagnosis, treatment and follow-up released in 2018, highlight, once again, the importance of biopsy with histological and mutational analyses to propose the $800 \mathrm{mg}$ imatinib dose for less sensitive KIT exon 9 mutations ${ }^{[24]}$.

KIT exon 11 GISTs are those patients who receive greater benefits from imatinib treatment compared with the other KIT mutational subtypes; indeed, these patients are twice as likely to respond to imatinib. In addition, KIT exon 11 show also higher response rate in terms of PFS and overall survival (OS). Primary mutations on KIT exon 13 characterize about $1 \%$ of GISTs; these genetic alterations promote changes within the receptors ATP binding pocket but the functional consequences have not been fully elucidate yet. The majority of data reported in literature show that mutations on KIT exon 13 confer sensitivity to imatinib, however a case report has described a rapid and aggressive tumor progression in a patient harboring a V654A alteration after imatinib and sunitinib treatment ${ }^{[33]}$.

With regard to PDGFRA, as mentioned before, carriers of D842V on exon 18 are usually primary resistant. PDGFRA D842V represents $\sim 70 \%$ of all PDGFRA mutations in GISTs ${ }^{[15]}$. Besides D842V, patients may harbor other alterations on exon 18 , which can hit close hotspots, as the aminoacids 843 to 845 , and commonly are represented by deletions; in this case, GISTs are sensitive to imatinib. Currently, the largest study so far conducted, investigating 289 PDGFRA mutant GISTs, showed a variable grade of imatinib sensitivity basing on the specific mutation ${ }^{[40]}$. By virtue of these variable responses to imatinib observed in PDGFRA mutant GISTs, lately, different PDGFRA inhibitors have been entered into clinical studies. Among those showing better results, crenolanib was tested in a phase 2 trial and showed important preliminary clinical claims ${ }^{[41]}$; these data have contributed to the initiation of a phase 3 randomized, placebo-controlled trial of crenolanib activity in PDGFRA D842V-mutant GISTs (NCT02847429) ${ }^{[42]}$.

Table 1 summarizes correlation between exons harboring primary mutations and clinical response $\mathrm{e}^{[43,44]}$.

\section{Resistance mutations}

As previously anticipated, progression after more than 6 months of initial clinical response is defined as secondary or acquired resistance. To date, secondary mutations have only been retrieved in patients with primary KIT mutations and rarely in those with primary PDGFRA mutations. Resistant mutations are most 
Table 1. Gastrointestinal stromal tumor sensitivity to the approved tyrosine-kinase inhibitors basing on primary mutational status

\begin{tabular}{lccc}
\hline Primary mutation & IM & SU & RE \\
\hline KIT exon 9 & $\mathrm{~S}^{\star}$ & $\mathrm{S}$ & $\mathrm{S}$ \\
KIT exon 11 & $\mathrm{~S}$ & $\mathrm{~S}$ & $\mathrm{~S}$ \\
PDGFRA exon 12 & $\mathrm{~S}$ & $\mathrm{~S}$ & $\mathrm{U}$ \\
PDGFRA exon 18 non D842V & $\mathrm{S}$ & $\mathrm{S}$ & $\mathrm{U}$ \\
PDGFRA exon 18 D842V & $\mathrm{R}$ & $\mathrm{R}$ & $\mathrm{R}$ \\
\hline
\end{tabular}

*800 mg instead of 400 mg/day. S: Sensitive; R: Resistant; U: Unknown; IM: imatinib; SU: sunitinib; RE: regorafenib

often found in the ATP-binding pocket of the kinase domain (exons 13 and 14) or in the kinase activation loop (exon 17 and 18$)^{[45]}$. Despite the acquisition of secondary mutations, delayed resistance may be due to different mechanisms, including the KIT overexpression caused by genomic amplification, KIT loss of expression with activation of an alternative tyrosine kinase, and ABC transporters overexpression ${ }^{[45]}$. Therapeutic management of GIST patients progressed on imatinib consider dose escalation from 400 to $800 \mathrm{mg} /$ day and/or switch to the second and third line TKIs.

The second line sunitinib inhibits several TKRs, blocking multiple biological processes, as tumor growth, angiogenesis and metastasis ${ }^{[46]}$. Sunitinib is effective in imatinib resistant GISTs and it has been shown that its activity is affected by the specific primary and secondary mutation ${ }^{[47]}$. In this context, exon 9 mutant patients usually have higher clinical benefits and objective response rates, compared with exon 11 mutants. In addition, both PFS and OS are generally significantly longer in KIT exon 9 mutant or KIT/PDGFRA WT GISTs with respect to KIT exon 11 mutant patients ${ }^{[47]}$. Taking into consideration the acquired mutations, sunitinib seems to be more effective in case of alterations within KIT exon 13 and 14 (ATP binding pocket) rather than those within KIT exon 17 or $18^{[47]}$.

Table 2 shows the correlation between the main secondary KIT mutations and sensitivity to approved TKIs.

\section{SDH deficient GISTs}

It is not surprising that KIT/PDGFRA WT GIST show poor response to imatinib and it has been reported that this GIST subset has a $76 \%$ higher risk of death if compared with KIT exon 11 mutants ${ }^{[36]}$. In this regard, the reports in literature agree in finding a very low benefit for these subsets of GISTs under imatinib treatment ${ }^{[\rho]}$. Furthermore, it seems that KIT/PDGFRA WT-SDH deficient GIST may have better response to sunitinib and regorafenib ${ }^{[9,48]}$. Sometimes, metastatic tumors can be quite indolent so that a "wait-and-see" policy applies, while other patients could benefit from resection. However, considering the complex molecular landscape of this subset, genetic counseling and therapeutic management plan in a GIST treatment center should be strongly taken into account.

\section{BRAF/RAS and NF1 mutant GISTs}

With regard to $B R A F$ status, in vitro studies showed that alterations on BRAF gene confer imatinib resistance $^{[49]}$ and, in general, to TKIs including sunitinib, regorafenib and sorafenib ${ }^{[0,51]}$. It has been proposed that this subset of GIST may have benefits from treatment with BRAF inhibitors, as dabrafenib, even if data are quite limited ${ }^{[51]}$.

The data on the prognosis of NF1 mutant GISTs are even more scarce and controversial. A first report showed a general good overall response in a long term follow-up, with only 5 out of 35 patients who died due to metastatic disease. On the contrary, two following case reports described NF1 mutant GISTs primary resistant or only initially responding to imatinib ${ }^{[52-54]}$. Currently, a Phase II Trial of evaluating MEK1/2 inhibitor, selumetinib, is ongoing for NF1 mutant GIST patients (NCT03109301). 
Table 2. Gastrointestinal stromal tumor sensitivity to the approved tyrosine-kinase inhibitors basing on secondary mutations

\begin{tabular}{llll}
\hline Secondary KIT mutation & IM & SU & RE \\
\hline KIT V654A & $\mathrm{R}$ & $\mathrm{S}$ & $\mathrm{R}$ \\
KIT T670I & $\mathrm{R}$ & $\mathrm{S}$ & $\mathrm{R}$ \\
KIT D816A/G/H/V & $\mathrm{R}$ & $\mathrm{R}$ & $\mathrm{R}$ \\
KIT D820A/E/G/Y & $\mathrm{R}$ & $\mathrm{R}$ & $\mathrm{S}$ \\
KIT N822H/K & $\mathrm{R} / \mathrm{S}$ & $\mathrm{R}$ & $\mathrm{S}$ \\
KIT Y823F & $\mathrm{R}$ & $\mathrm{R}$ & $\mathrm{S}$ \\
KIT A829P & $\mathrm{R} / \mathrm{S}$ & $\mathrm{R}$ & $\mathrm{S}$ \\
\hline
\end{tabular}

S: Sensitive; R: Resistant; R/S: intermediate sensitivity; IM: imatinib; SU: sunitinib; RE: regorafenib

\section{GERMLINE DNA ALTERATIONS IN GIST}

As reviewed, imatinib has represented a groundbreaking in GIST history. After its introduction, a huge research effort has been directed to the identification of driver mechanisms of acquired resistance, as well as, novel potential biomarkers for GIST treatment. In this context, the involvement of pharmacogenetic and epigenetic mechanisms in TKIs resistance has been investigated. In particular, with regard to pharmacogenetics, any drug goes through a specific pharmacokinetics itinerary that might be relevant for both drug efficacy and toxicity ${ }^{[5,56]}$. Therefore, it is conceivable that polymorphisms or gene expression regulation through methylation/miRNA mechanisms could represent key players in affecting the final clinical outcome. By virtue of this consideration, possible pharmacogenetic ${ }^{[57-62]}$ and epigenetic ${ }^{[63-66]}$ mechanisms of imatinib and sunitinib resistance have been broadly investigated in GISTs ${ }^{[67-71]}$. Despite the extensive research, data are controversial and to date none of them supports the use of pharmacogenetic or pharmacoepigenetic tests to optimize treatment outcome in GIST patients.

\section{CONCLUSION}

This review aimed to point out the complex landscape of GISTs. This family of tumors is quite heterogeneous and any oncologist and clinical pharmacologist should consider every case individually, in order to deeply and accurately characterize the molecular events driving tumorigenis and treatment response. Currently, we know that GIST mutational status genotype has diverse impact on the therapeutic decision-making and this should be at the base of the clinical GIST management [Table 1]. For this reason, the tumor genetic consult should be crucial and strongly suggested by the oncologists who care the patients. However, in the era of personalized medicine, the unmet need for a precision medicine approach in GIST is more pivotal than ever. Indeed, although the currently available data points out that the tumor mutational status weighs more than the germinal one, the healthy patient's DNA is still relevant. Therefore, even the currently available evidence do not allow translation of genetic test into routine clinical practice, implementation of pharmacokinetics, supported by trials, is needed.

\section{DECLARATIONS}

\section{Authors' contributions}

Wrote the manuscript: Ravegnini G, Angelini S

Revised the manuscript: Hrelia P

\section{Availability of data and materials}

Not applicable.

\section{Financial support and sponsorship}

This work was supported by the Ministry of Education, University and Research of Italy (MIUR) (2015Y3C5KP_002) to Angelini S; the L'Oréal-UNESCO for Women and Science Award to Ravegnini G. 


\section{Conflicts of interest}

All authors declared that there are no conflicts of interest.

\section{Ethical approval and consent to participate}

Not applicable.

\section{Consent for publication}

Not applicable.

\section{Copyright}

(c) The Author(s) 2019.

\section{REFERENCES}

1. Mei L, Du W, Idowu M, von Mehren M, Boikos SA. Advances and challenges on management of gastrointestinal stromal tumors. Front Oncol 2018;8:135.

2. Corless CL, Fletcher JA, Heinrich MC. Biology of gastrointestinal stromal tumors. J Clin Oncol 2004;22:3813-25.

3. Hirota S, Isozaki K, Moriyama Y, Hashimoto K, Nishida T, et al. Gain-of-function mutations of c-kit in human gastrointestinal stromal tumors. Science 1998;279:577-80.

4. Ravegnini G, Sammarini G, Angelini S, Hrelia P. Pharmacogenetics of tyrosine kinase inhibitors in gastrointestinal stromal tumor and chronic myeloid leukemia. Expert Opin Drug Metab Toxicol 2016;12:733-42.

5. Ricci R, Dei Tos AP, Rindi G. GISTogram: a graphic presentation of the growing GIST complexity. Virchows Arch 2013;463:481-7.

6. Miettinen M, Lasota J. Gastrointestinal stromal tumors. Gastroenterol Clin North Am 2013;42:39.

7. Nannini M, Urbini M, Astolfi A, Biasco G, Pantaleo MA. The progressive fragmentation of the KIT/PDGFRA wild-type (WT) gastrointestinal stromal tumors (GIST). J Transl Med 2017;15:113.

8. Mei L, Smith SC, Faber AC, Trent J, Grossman SR, et al. Gastrointestinal stromal tumors: the GIST of precision medicine. Trends Cancer 2018;4:74-91.

9. Boikos SA, Pappo AS, Killian JK, LaQuaglia MP, Weldon CB, et al. Molecular subtypes of KIT/PDGFRA wild-type gastrointestinal stromal tumors: a report from the national institutes of health gastrointestinal stromal tumor clinic. JAMA Oncol 2016;2:922-8.

10. Corless CL, Barnett CM, Heinrich MC. Gastrointestinal stromal tumours: origin and molecular oncology. Nat Rev Cancer 2011;11:865-78.

11. Indio V, Astolfi A, Tarantino G, Urbini M, Patterson J, et al. Integrated molecular characterization of gastrointestinal stromal tumors (GIST) harboring the rare D842V mutation in PDGFRA gene. Int J Mol Sci 2018;19:732.

12. Angelini S, Ravegnini G, Fletcher JA, Maffei F, Hrelia P. Clinical relevance of pharmacogenetics in gastrointestinal stromal tumor treatment in the era of personalized therapy. Pharmacogenomics 2013;14:941-56.

13. de Melo Maia B, Lavorato-Rocha AM, Rodrigues IS, Baiocchi G, Cestari FM, et al. Prognostic significance of c-KIT in vulvar cancer: bringing this molecular marker from bench to bedside. J Transl Med 2012;10:150.

14. Hirota S, Ohashi A, Nishida T, Isozaki K, Kinoshita K, et al. Gain-of-function mutations of platelet-derived growth factor receptor alpha gene in gastrointestinal stromal tumors. Gastroenterology 2003;125:660-7.

15. Heinrich MC, Corless CL, Duensing A, McGreevey L, Chen CJ, et al. PDGFRA activating mutations in gastrointestinal stromal tumors. Science 2003;299:708-10.

16. Huss S, Elges S, Trautmann M, Sperveslage J, Hartmann W, et al. Classification of KIT/PDGFRA wild-type gastrointestinal stromal tumors: implications for therapy. Expert Rev Anticancer Ther 2015;15:623-8.

17. Kumar R, Angelini S, Hemminki K. Activating BRAF and N-Ras mutations in sporadic primary melanomas: an inverse association with allelic loss on chromosome 9. Oncogene 2003;22:9217-24.

18. Scherer D, Rachakonda PS, Angelini S, Mehnert F, Sucker A, et al. Association between the germline MC1R variants and somatic BRAF/NRAS mutations in melanoma tumors. J Invest Dermatol 2010;130:2844-8.

19. Dankner M, Rose AAN, Rajkumar S, Siegel PM, Watson IR. Classifying BRAF alterations in cancer: new rational therapeutic strategies for actionable mutations. Oncogene 2018;37:3183-99.

20. Ravegnini G, Quero G, Sammarini G, Giustiniani MC, Castri F, et al. Gastrointestinal juvenile-like (inflammatory/hyperplastic) mucosal polyps in neurofibromatosis type 1 with no concurrent genetic or clinical evidence of other syndromes. Virchows Arch 2019;474:259-64.

21. Urbini M, Astolfi A, Indio V, Heinrich MC, Corless CL, et al. SDHC methylation in gastrointestinal stromal tumors (GIST): a case report. BMC Med Genet 2015;16:87.

22. Miettinen M, Lasota J. Succinate dehydrogenase deficient gastrointestinal stromal tumors (GISTs) - a review. Int J Biochem Cell Biol 2014;53:514-9.

23. Pantaleo MA, Astolfi A, Urbini M, Nannini M, Paterini P, et al. Analysis of all subunits, SDHA, SDHB, SDHC, SDHD, of the succinate dehydrogenase complex in KIT/PDGFRA wild-type GIST. Eur J Hum Genet 2014;22:32-9.

24. Casali PG, Abecassis N, Bauer S, Biagini R, Bielack S, et al. Gastrointestinal stromal tumours: ESMO-EURACAN clinical practice guidelines for diagnosis, treatment and follow-up. Ann Oncol 2018;29(Supplement_4):iv68-78. 
25. Akahoshi K, Oya M, Koga T, Shiratsuchi Y. Current clinical management of gastrointestinal stromal tumor. World J Gastroenterol 2018;24:2806-17.

26. ESMO/European Sarcoma Network Working Group. Gastrointestinal stromal tumours: ESMO clinical practice guidelines for diagnosis, treatment and follow-up. Ann Oncol 2014;25 Suppl 3:iii21-6.

27. Demetri GD, von Mehren M, Blanke CD, Van den Abbeele AD, Eisenberg B, et al. Efficacy and safety of imatinib mesylate in advanced gastrointestinal stromal tumors. N Engl J Med 2002;347:472-80.

28. Maleddu A, Pantaleo MA, Nannini M, Di Battista M, Saponara M, et al. Mechanisms of secondary resistance to tyrosine kinase inhibitors in gastrointestinal stromal tumours (Review). Oncol Rep 2009;21:1359-66.

29. Demetri GD, van Oosterom AT, Garrett CR, Blackstein ME, Shah MH, et al. Efficacy and safety of sunitinib in patients with advanced gastrointestinal stromal tumour after failure of imatinib: a randomised controlled trial. Lancet 2006;368:1329-38.

30. George S, Wang Q, Heinrich MC, Corless CL, Zhu M, et al. Efficacy and safety of regorafenib in patients with metastatic and/or unresectable GI stromal tumor after failure of imatinib and sunitinib: A multicenter phase II trial. J Clin Oncol 2012;30:2401-7.

31. Papaetis GS, Syrigos KN. Sunitinib: a multitargeted receptor tyrosine kinase inhibitor in the era of molecular cancer therapies. BioDrugs 2009;23:377-89.

32. Vincenzi B, Nannini M, Grignani G, Fumagalli E, Gasperoni S, et al. Rechallenge in advanced GIST progressing to imatinib, sunitinib and regorafenib: an Italian survey. J Clin Oncol 2017;35:11038.

33. Housman G, Byler S, Heerboth S, Lapinska K, Longacre M, et al. Drug resistance in cancer: an overview. Cancers (Basel) 2014;6:1769-92.

34. Lee JH, Kim Y, Choi JW, Kim YS. Correlation of imatinib resistance with the mutational status of KIT and PDGFRA genes in gastrointestinal stromal tumors: a meta-analysis. J Gastrointestin Liver Dis 2013;22:413-8.

35. Künstlinger H, Huss S, Merkelbach-Bruse S, Binot E, Kleine MA, et al. Gastrointestinal stromal tumors with KIT exon 9 mutations: update on genotype-phenotype correlation and validation of a high-resolution melting assay for mutational testing. Am J Surg Pathol 2013;37:1648-59.

36. Debiec-Rychter M, Sciot R, Le Cesne A, Schlemmer M, Hohenberger P, et al. KIT mutations and dose selection for imatinib in patients with advanced gastrointestinal stromal tumours. Eur J Cancer 2006;42:1093-103.

37. Heinrich MC, Owzar K, Corless CL, Hollis D, Borden EC, et al. Correlation of kinase genotype and clinical outcome in the North American intergroup phase III trial of imatinib mesylate for treatment of advanced gastrointestinal stromal tumor: CALGB 150105 study by cancer and leukemia group B and Southwest oncology group. J Clin Oncol 2008;26:5360-7.

38. Casali PG, Zalcberg J, Le Cesne A, Reichardt P, Blay JY, et al. Ten-year progression-free and overall survival in patients with unresectable or metastatic GI stromal tumors: long-term analysis of the European organisation for research and treatment of cancer, Italian sarcoma group, and Australasian gastrointestinal trials group intergroup phase III randomized trial on imatinib at two dose levels. J Clin Oncol 2017;35:1713-20.

39. Kikuchi H, Miyazaki S, Setoguchi T, Hiramatsu Y, Ohta M, et al. Rapid relapse after resection of a sunitinib-resistant gastrointestinal stromal tumor harboring a secondary mutation in exon 13 of the c-KIT gene. Anticancer Res 2012;32:4105-9.

40. Corless CL, Schroeder A, Griffith D, Town A, McGreevey L, et al. PDGFRA mutations in gastrointestinal stromal tumors: frequency, spectrum and in vitro sensitivity to imatinib. J Clin Oncol 2005;23:5357-64.

41. Blay JY, Heinrich MC, Hohenberger P, Casali PG, Rutkowski P, et al. A randomized, double-blind, placebo-controlled, phase III study of crenolanib in advanced or metastatic GIST patients bearing a D842V mutation in PDGFRA: the CrenoGIST study. J Clin Oncol 2017;35:TPS11080

42. Klug LR, Kent JD, Heinrich MC. Structural and clinical consequences of activation loop mutations in class III receptor tyrosine kinases. Pharmacol Ther 2018;191:123-34.

43. Heinrich MC, Rankin C, Blanke CD, Demetri GD, Borden EC, et al. Correlation of long-term results of imatinib in advanced gastrointestinal stromal tumors with next-generation sequencing results. JAMA Oncol 2017;3:944-52.

44. Oppelt PJ, Hirbe AC, Van Tine BA. Gastrointestinal stromal tumors (GISTs): point mutations matter in management, a review. J Gastrointest Oncol 2017;8:466-73.

45. Gounder MM, Maki RG. Molecular basis for primary and secondary tyrosine kinase inhibitor resistance in gastrointestinal stromal tumor. Cancer Chemother Pharmacol 2011;67:25-43.

46. Aparicio-Gallego G, Blanco M, Figueroa A, García-Campelo R, Valladares-Ayerbes M, et al. New insights into molecular mechanisms of sunitinib-associated side effects. Mol Cancer Ther 2011;10:2215-23.

47. Heinrich MC, Maki RG, Corless CL, Antonescu CR, Harlow A, et al. Primary and secondary kinase genotypes correlate with the biological and clinical activity of sunitinib in imatinib-resistant gastrointestinal stromal tumor. J Clin Oncol 2008;26:5352-9.

48. Ben-Ami E, Barysauskas CM, von Mehren M, Heinrich MC, Corless CL, et al. Long-term follow-up results of the multicenter phase II trial of regorafenib in patients with metastatic and/or unresectable GI stromal tumor after failure of standard tyrosine kinase inhibitor therapy. Ann Oncol 2016;27:1794-9.

49. Miranda C, Nucifora M, Molinari F, Conca E, Anania MC, et al. KRAS and BRAF mutations predict primary resistance to imatinib in gastrointestinal stromal tumors. Clin Cancer Res 2012;18:1769-76.

50. Franck C, Rosania R, Franke S, Haybaeck J, Canbay A, et al. The BRAF status may predict response to sorafenib in gastrointestinal stromal tumors resistant to imatinib, sunitinib, and regorafenib: case series and review of the literature. Digestion 2019;99:179-84.

51. Falchook GS, Trent JC, Heinrich MC, Beadling C, Patterson J, et al. BRAF mutant gastrointestinal stromal tumor: first report of regression with BRAF inhibitor dabrafenib (GSK2118436) and whole exomic sequencing for analysis of acquired resistance. Oncotarget 2013;4:310-5.

52. Mussi C, Schildhaus HU, Gronchi A, Wardelmann E, Hohenberger P. Therapeutic consequences from molecular biology for 
gastrointestinal stromal tumor patients affected by neurofibromatosis type 1. Clin Cancer Res 2008;14:4550-5.

53. Lee JL, Kim JY, Ryu MH, Kang HJ, Chang HM, et al. Response to imatinib in KIT- and PDGFRA-wild type gastrointestinal stromal associated with neurofibromatosis type 1. Dig Dis Sci 2006;51:1043-6.

54. Miettinen M, Fetsch JF, Sobin LH, Lasota J. Gastrointestinal stromal tumors in patients with neurofibromatosis 1: a clinicopathologic and molecular genetic study of 45 cases. Am J Surg Pathol 2006;30:90-6.

55. Caudle KE, Gammal RS, Whirl-Carrillo M, Hoffman JM, Relling MV, et al. Evidence and resources to implement pharmacogenetic knowledge for precision medicine. Am J Heal Pharm 2016;73:1977-85.

56. Ravegnini G, Nannini M, Sammarini G, Astolfi A, Biasco G, et al. Personalized medicine in gastrointestinal stromal tumor (GIST): clinical implications of the somatic and germline DNA analysis. Int J Mol Sci 2015;16:15592-608.

57. Eechoute K, Sparreboom A, Burger H, Franke RM, Schiavon G, et al. Drug transporters and imatinib treatment: implications for clinical practice. Clin Cancer Res 2011;17:406-15.

58. Verboom MC, Kloth JSL, Swen JJ, van der Straaten T, Bovée JVMG, et al. Genetic polymorphisms in angiogenesis-related genes are associated with worse progression-free survival of patients with advanced gastrointestinal stromal tumours treated with imatinib. Eur J Cancer 2017;86:226-32.

59. Zhang Q, Xu J, Qian Y, Chen L, Li Q, et al. Association of imatinib plasma concentration and single-nucleotide polymorphisms with adverse drug reactions in patients with gastrointestinal stromal tumors. Mol Cancer Ther 2018;17:2780-7.

60. Liu J, Chen Z, Chen H, Hou Y, Lu W, et al. Genetic polymorphisms contribute to the individual variations of imatinib mesylate plasma levels and adverse reactions in chinese GIST patients. Int J Mol Sci 2017;18:603.

61. Kloth JSL, Verboom MC, Swen JJ, van der Straaten T, Sleijfer S, et al. Genetic polymorphisms as predictive biomarker of survival in patients with gastrointestinal stromal tumors treated with sunitinib. Pharmacogenomics J 2018;18:49-55.

62. Saif MW, Smith MH, Maloney A, Diasio RB. Imatinib-induced hyperbilirubinemia with UGT1A1 (*28) promoter polymorphism: first case series in patients with gastrointestinal stromal tumor. Ann Gastroenterol 2016;29:551-6.

63. Yang J, Ikezoe T, Nishioka C, Takezaki Y, Hanazaki K, et al. Long-term exposure of gastrointestinal stromal tumor cells to sunitinib induces epigenetic silencing of the PTEN gene. Int J cancer 2012;130:959-66.

64. Jasek K, Kasubova I, Holubekova V, Stanclova A, Plank L, et al. Epigenetics: an alternative pathway in GISTs tumorigenesis. Neoplasma 2018;65:477-93.

65. Yun S, Kim WK, Kwon Y, Jang M, Bauer S, et al. Survivin is a novel transcription regulator of KIT and is downregulated by miRNA-494 in gastrointestinal stromal tumors. Int J cancer 2018;142:2080-93.

66. Zhang Z, Jiang NY, Guan RY, Zhu YK, Jiang FQ, et al. Identification of critical microRNAs in gastrointestinal stromal tumor patients treated with Imatinib. Neoplasma 2018;65:683-92.

67. Pantaleo MA, Ravegnini G, Astolfi A, Simeon V, Nannini M, et al. Integrating miRNA and gene expression profiling analysis revealed regulatory networks in gastrointestinal stromal tumors. Epigenomics 2016;8:1347-66.

68. Ravegnini G, Urbini M, Simeon V, Genovese C, Astolfi A, et al. An exploratory study by DMET array identifies a germline signature associated with imatinib response in gastrointestinal stromal tumor. Pharmacogenomics J 2018; doi: 10.1038/s41397-018-0050-4.

69. Angelini S, Ravegnini G, Nannini M, Bermejo JL, Musti M, et al. Folate-related polymorphisms in gastrointestinal stromal tumours: susceptibility and correlation with tumour characteristics and clinical outcome. Eur J Hum Genet 2015;23:817-23.

70. Ravegnini G, Nannini M, Simeon V, Musti M, Sammarini G, et al. Polymorphisms in DNA repair genes in gastrointestinal stromal tumours: susceptibility and correlation with tumour characteristics and clinical outcome. Tumour Biol 2016;37:13413-23

71. Angelini S, Pantaleo MA, Ravegnini G, Zenesini C, Cavrini G, et al. Polymorphisms in OCTN1 and OCTN2 transporters genes are associated with prolonged time to progression in unresectable gastrointestinal stromal tumours treated with imatinib therapy. Pharmacol Res 2013;68:1-6. 